(c) American Dairy Science Association, 2002.

\title{
Field Validation of a Milk-line Sampling Device for Monitoring Milk Component Data
}

\author{
S. Godden, ${ }^{*}$ R. Bey,† J. Reneau, $¥$ R. Farnsworth, ${ }^{\star}$ and M. LaValle† \\ *Department of Clinical and Population Medicine, \\ †Department of Pathobiology, and \\ $\ddagger$ Department of Animal Science, \\ University of Minnesota, St. Paul 55108
}

\begin{abstract}
The objective of this study was to investigate the ability of a milk-line sampling device to obtain a representative sample under field conditions by comparing the milk component composition between milk-line and bulk-tank samples, for milk harvested from the same group of cows at the same milking. A total of 42 paired milk-line and bulk-tank samples were collected at separate milking events from 21 different dairy herds. Samples were analyzed for milk fat (\%), true protein (\%), and milk urea nitrogen $(\mathrm{mg} / \mathrm{dl})$. Concordance correlation coefficients showed a very high level of agreement between the two sample types, with values ranging between 0.82 and 0.95 for the components measured. ANOVA showed that milk component data derived from milk-line samples were neither statistically nor numerically different from milk component data derived from bulk-tank samples. The strategy of monitoring milk component data through milk line sampling should provide dairy producers with inexpensive, timely, and accurate information that will help to improve ongoing nutritional monitoring programs for individual groups of cows within the dairy herd.
\end{abstract}

(Key words: milk-line sampling, milk fat, true protein, milk urea nitrogen)

Abbreviation key: MUN = milk urea nitrogen .

\section{INTRODUCTION}

The utility of monitoring milk components such as milk fat and protein concentrations as a dairy herd management tool, and specifically as a nutritional monitoring tool, has been well established and well utilized (Fetrow et al., 1987; Azzam et al., 1989; Nelson, 1994; Wiggans, 1994; Studer, 1998). More recently, researchers have also demonstrated the utility of measuring

Received September 27, 2001.

Accepted February 2, 2002.

Corresponding author: S. Godden; e-mail: godde002@tc.umn.edu. milk urea nitrogen (MUN) concentrations as a tool to aid in monitoring nutritional management programs (Oltner and Wiktorsson, 1983; Hof et al., 1997; Jonker et al., 1998; Schepers and Meijer, 1998; Godden et al., 2001). Traditional sampling methods for monitoring milk components have included individual cow sampling (through DHIA on test day) or bulk-tank testing (through milk processors at each pick-up). However, a new strategy, collecting samples from individual groups of cows directly out of the milk line, is currently being adopted on some larger dairies. These sampling devices are typically placed in the milk line past the receiver and past the plate cooler, if one is present in the system. Milk-line samples may be particularly attractive to larger herds because they allow producers to monitor the performance of individual groups of cows within the herd. And, because relatively few samples are submitted at any one milking, the overall program cost is relatively inexpensive. As such, producers can opt for more frequent milk sampling schedules. This should improve the monitoring program by increasing the producer's ability more quickly to detect changes in any one group's performance.

While the potential benefits of milk-line sampling are obvious, little independent research has been performed to ensure that the sampling systems currently available can, when used under field conditions, collect a sample that is truly representative of all cows within the group of interest. If the line sampling device were functioning properly, and so collecting a consistently metered sample, then one would expect that the composition of the line sample should be nearly identical to the milk entering the bulk tank from that same group of cows. The objective of this study was to determine whether a milk-line sampling device used in a farm setting could obtain a representative sample that would be useful in a diagnostic context for nutritional monitoring programs. This was done by comparing the milk component composition (milk fat, true protein and MUN) between milk-line and bulk-tank samples for milk harvested from the same group of cows. 


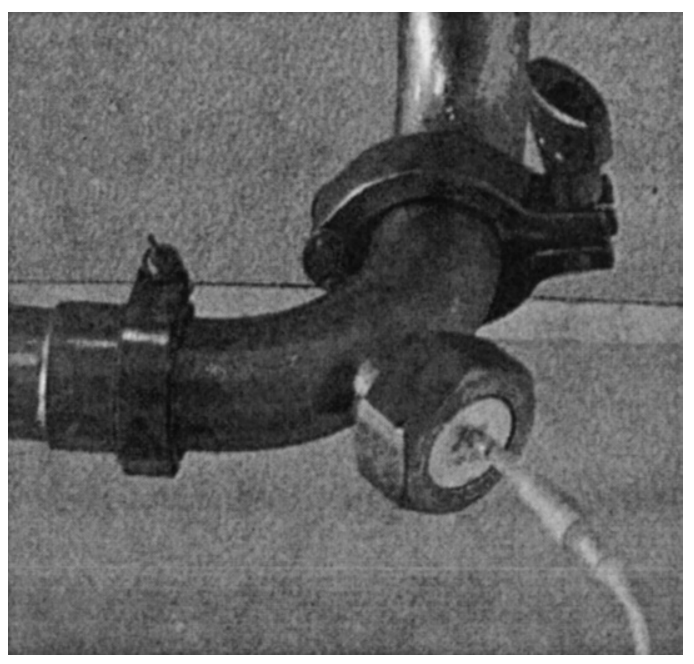

Figure 1. QMI Safe Septum sani-elbow (Quality Management, Inc., Oakdale, MN) placed in milk line.

\section{MATERIALS AND METHODS}

\section{Herd Enrollment and Sampling Period}

Twenty-one dairy herds in Minnesota and western Wisconsin were purposely selected to participate in the study based on their willingness to participate and to provide a broad range of milk component and bacterial culture measures. Sample collection occurred between February and August 2001. Repeated sampling did occur at separate milkings in some herds.

\section{Sample Collection and Analysis}

Sampling occurred during the milking immediately following a previous milk pick-up (i.e., started with an empty bulk tank). Before beginning milking, the QMI Safe Septum sani-elbow (Quality Management, Inc., Oakdale, MN) was placed in the milk line past the receiver jar and past the plate cooler, if one was present in the system. The sampler was positioned such that the sampling port was on the bottom or side of the line, where possible. A 16-gauge 1.5-inch needle was placed through the sampler diaphragm with the bevel of the needle pointed toward the flow of milk in the line (Figure 1). If the port could only be positioned on the top of the line, then a 16-gauge 3 -inch needle was used to reach across the elbow and allow the bevel opening still to be on the bottom of the line, in order to get a sufficient flow rate. A sterile fluid administration set was then attached to the sampling needle to collect milk, by gravity flow, into a sterile collection container (sterilized bag or 1-gallon bottle [Figure 2]). The flow regulator on the fluid line was used to establish a consistent flow

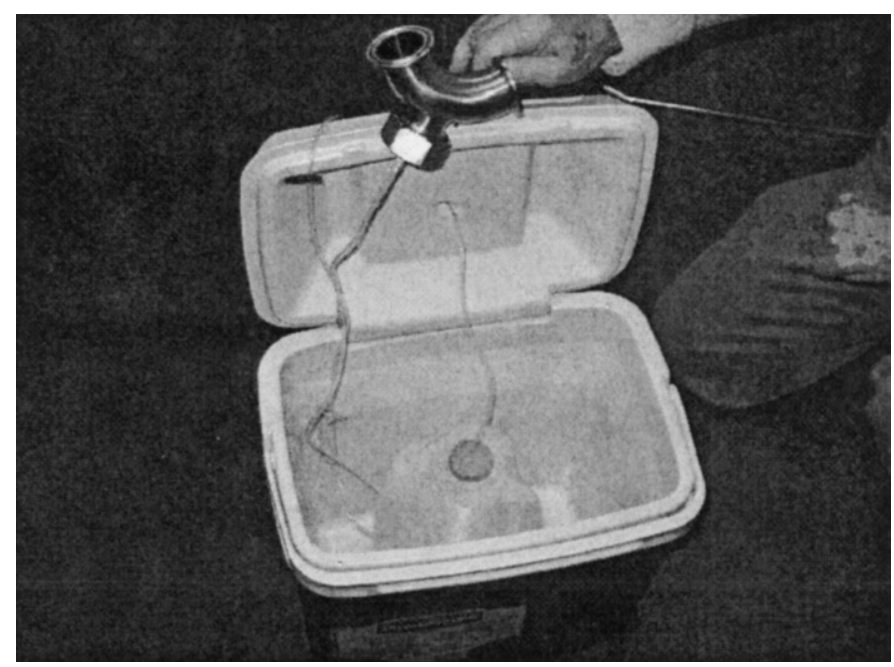

Figure 2. QMI Safe Septum sani-elbow (Quality Management, Inc., Oakdale, MN) attached to sampling line and sample container.

rate throughout the sample collection process. Flow regulation was handled differently depending on whether the flow in the line was intermittent or continuous: if milk flow was continuous, as with a variable frequency drive milk pump, then a steady drip or stream was collected. If milk flow was intermittent, as with a conventional liquid-level-control milk pump, then flow regulation was set so that approximately 10 to $15 \mathrm{ml}$ was collected each time the milk pump operated. A total sample volume of $200 \mathrm{ml}$ or greater was collected, at an even sampling rate, over the course of the entire milking. Samples were kept cool while being collected, by placing the collection container in an insulated cooler surrounded by ice or ice packs. Upon completion of the milking process, the collection container was mixed thoroughly and a subsample was collected from the sample collection container into a sterile $30-\mathrm{ml}$ vial. A bulk-tank sample was also then collected into a sterile 30-ml vial.

Upon completion of the collection process, the paired samples were refrigerated and then transported directly to the Udder Health Laboratory at the University of Minnesota. Here, one subsample each from both the milk-line and bulk-tank samples was used for bacteriological culture at the udder health laboratory (culture data not discussed in this paper), whereas a second subsample was submitted for routine analysis of components in a certified laboratory, DQCI Services Laboratory (Dairy Quality Control Institute, Mounds View, MN). MUN concentration was determined using the Bentley ChemSpec instrument (Bentley Instruments, Inc., Chaska, MN). Milk fat and true protein results were produced using a Bentley 2000 Infrared instrument (Bentley Instruments, Inc.). Calibaration of this 
Table 1. Comparison of milk component measures between milk-line and bulk-tank milk samples.

\begin{tabular}{|c|c|c|c|c|}
\hline \multirow{2}{*}{$\begin{array}{l}\text { Milk } \\
\text { component } \\
(\mathrm{n}=42)\end{array}$} & \multicolumn{2}{|c|}{$\begin{array}{c}\text { Sample type } \\
\text { Mean (+/- SD) (range) }\end{array}$} & \multirow{2}{*}{$\begin{array}{l}\text { Concordance } \\
\text { correlation } \\
\text { coefficient }\end{array}$} & \multirow{2}{*}{$\begin{array}{l}\text { ANOVA results } \\
\text { est. difference }(+/-\mathrm{SD}) \\
(P \text {-value })\end{array}$} \\
\hline & Bulk tank & Milk line & & \\
\hline Milk fat (\%) & $\begin{array}{l}3.73(0.34) \\
(3.18-4.45)\end{array}$ & $\begin{array}{l}3.75(0.43) \\
(2.81-4.49)\end{array}$ & 0.87 & $\begin{array}{l}0.02(0.053) \\
(0.70)\end{array}$ \\
\hline True protein $(\%)$ & $\begin{array}{l}3.05(0.15) \\
(2.83-3.40)\end{array}$ & $\begin{array}{l}3.03(0.19) \\
(2.59-3.42)\end{array}$ & 0.82 & $\begin{array}{l}-0.018(0.026) \\
(0.49)\end{array}$ \\
\hline $\mathrm{MUN}^{1}(\mathrm{mg} / \mathrm{dl})$ & $\begin{array}{l}15.41(2.09) \\
(11.4-22.0)\end{array}$ & $\begin{array}{l}15.21(2.18) \\
(11.1-21.6)\end{array}$ & 0.95 & $\begin{array}{l}-0.17(0.29) \\
(0.56)\end{array}$ \\
\hline
\end{tabular}

${ }^{1}$ Milk urea nitrogen.

machine was checked at least twice daily and standard "A" and "B" (high and low) samples were run hourly.

\section{Statistical Analysis}

Descriptive statistics were produced describing the mean, variation, and range for milk fat, true protein and MUN, for both milk-line and bulk-tank milk samples. A concordance correlation coefficient was calculated to measure agreement between the two sample types for each milk component, and a scatter plot was created for milk fat, true protein, and MUN, plotting milk-line against bulk-tank sample results. Finally, ANOVA (Proc Mixed in SAS; 1996) was used to determine whether, for each milk component of interest (outcome variable), the measure differed depending on the sample type (explanatory variable). In addition to the main effect of sample type (milk-line vs. bulk-tank sample), each model also controlled for random herd effects, given that repeated sampling had occurred in some of the study herds. Statistical significance for all comparisons was set at $P<0.05$.

\section{RESULTS}

A total of 42 paired samples were collected from 21 herds, with a mean of two sampling events occurring for each herd (median $=1, \mathrm{SD}=2.7$, range $=1$ to 12 ). The final number of paired samples collected in this study should have allowed us to be able to detect the following minimum differences between bulk-tank and milk-line sample results, should a difference have truly existed:

1) Milk fat: difference of $\geq 0.15 \%$ (alpha of $10 \%$, beta of $80 \%$ )

2) True protein: difference of $\geq 0.10 \%$ (alpha of $5 \%$, beta of $80 \%$ )

3) MUN: difference of $\geq 1.0 \mathrm{mg} / \mathrm{dl}$ (alpha of $5 \%$, beta of $80 \%$ )

A description of the concentrations of milk fat, true protein, and MUN measured for the two sample types are presented in Table 1 (mean, SD, range). Concor- dance correlation coefficients comparing bulk-tank versus milk-line sample results showed a very high degree of correlation, ranging between 0.82 and 0.95 for milk fat, true protein, and MUN (Table 1). ANOVA indicated no difference between bulk-tank and milk-line samples for any of the milk components measured $(P>0.05$ [Table 1]). Graphs plotting bulk-tank versus milk-line sample results for milk fat, true protein, and MUN are presented in Figures 3, 4, and 5, respectively.

\section{DISCUSSION}

Sampling methods for monitoring milk components have traditionally been limited to either individual cow samples, usually collected by DHIA field staff on test day, or bulk-tank samples, routinely tested and reported by milk processors after each pick-up. Advantages of measuring individual cow samples through DHIA testing include the ability to monitor individual cow performance, to calculate and monitor average group performance, and to monitor variation among individuals or groups of cows, or changes within individuals or groups of cows over time. A major disadvantage

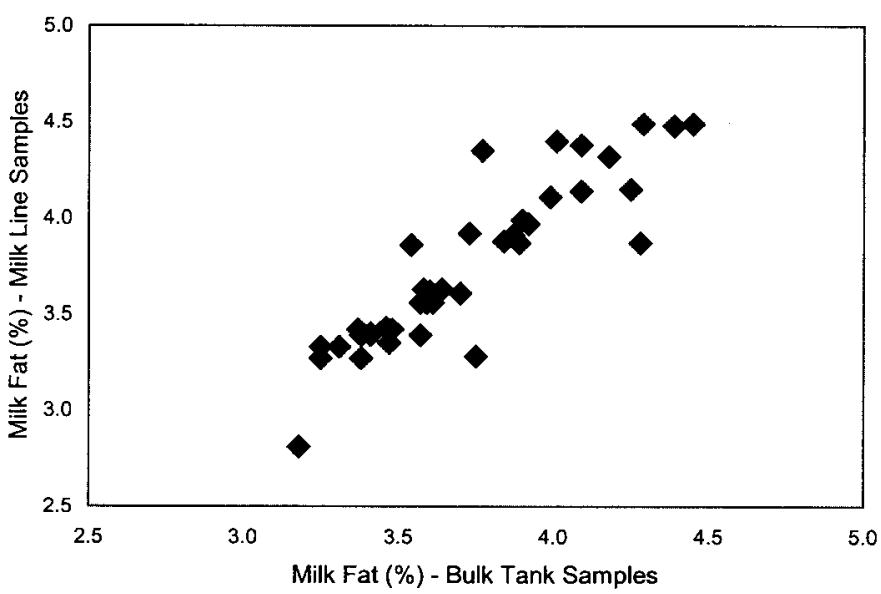

Figure 3. Bulk-tank versus milk-line sample milk fat results. 


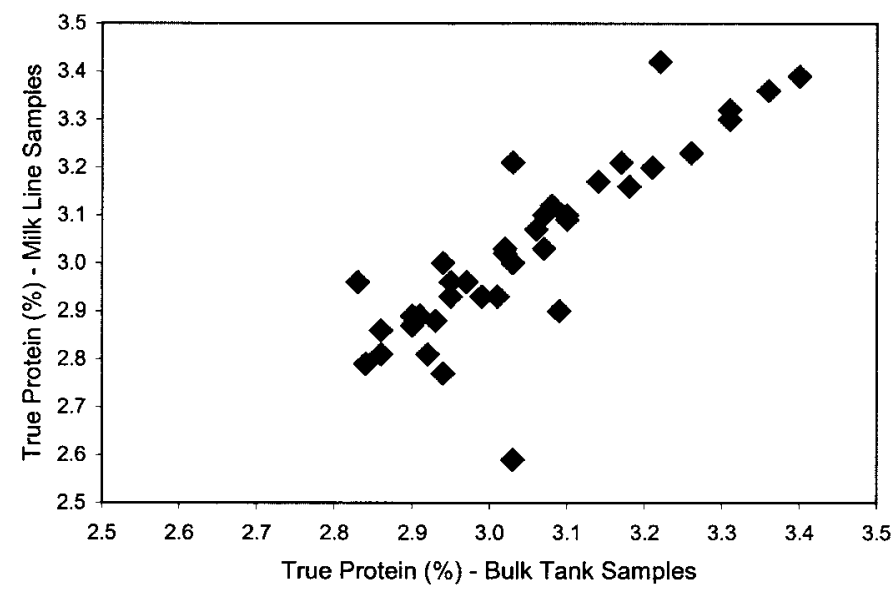

Figure 4. Bulk-tank versus milk-line sample milk true protein results.

of this testing strategy is, however, that the relatively infrequent testing schedule (usually once per month or less frequently) means producers may not be able quickly to detect and respond to changes in animal or group performance. However, more frequent individual cow testing through DHIA to provide more timely information is too labor-intensive and costly to warrant routine adoption. Similarly, the bulk-tank sampling strategy also carries its own set of advantages and disadvantages. Because bulk-tank analysis of components is provided with every shipment of milk, producers receive frequent, timely, and inexpensive information about the herd's performance. However, because analysis is of a single pooled sample, producers are unable to measure the average performance of any one group of cows, unable to measure variation among different groups,

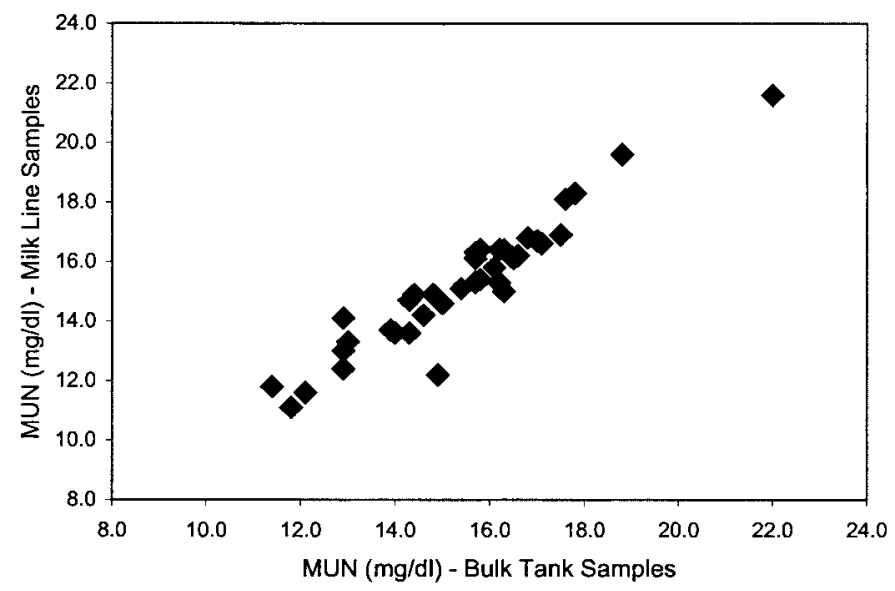

Figure 5. Bulk-tank versus milk-line sample milk urea nitrogen (MUN) results. and unable to detect changes occurring within groups of cows over time.

The milk-line sampling strategy addresses many of the limitations previously discussed for either individual cow or bulk tank sampling strategies. Producers can conveniently monitor the performance of several different groups of cows within the herd. And, because relatively few samples are still submitted at any one milking, a routine testing program is relatively inexpensive. As such, producers can opt for more frequent sampling schedules. This more timely information should improve the monitoring program by increasing the producer's ability to detect a recent change in any one group's performance. However, before the routine adoption of new sampling strategies such as milk-line sampling, their application should be independently validated in a farm setting and in a diagnostic context (i.e., as a diagnostic tool for nutritional monitoring at the group level). Potential sources of disagreement between milk-line and bulk-tank samples could include incorrect installation of the in-line sampling unit, inconsistent flow regulation through the sampling device, or failure to thoroughly agitate the bulk tank before bulk-tank sample collection.

High concordance correlation coefficients in this study indicated that agreement between the two sample types ranged from very good to excellent for the milk components of interest (range $=0.82$ to 0.95 ). Only a very small, and statistically nonsignificant, numerical difference was observed between bulk-tank and milkline sample results for any of the three major components of interest: milk fat estimated difference $=0.02 \%$ ( $\mathrm{SD}=0.053, P=0.70$ ); true protein estimated difference $=-0.018 \%(\mathrm{SD}=0.026, P=0.49) ;$ MUN estimated difference $=-0.17 \mathrm{mg} / \mathrm{dl}(\mathrm{SD}=0.29, P=0.56)$. In addition to being statistically "not different," these very small numerical differences were not large enough to result in errors of interpretation or in the management decisions derived from monitoring this type of data.

One issue not addressed in this study, because the milk line samples collected represented an entire milking, was whether there is much opportunity for the carryover of milk in the line from a previous group to commingle with milk from the current group of cows being sampled, potentially leading to inaccurate results. While the potential for carryover between successive groups is real, the influence of the relatively small volume of carryover milk actually sampled should be minor, once diluted with the significantly larger volume of milk collected from the current group. This issue is potentially more important when considering its impact on bacterial culture results (not discussed in this paper) than with milk component data. One possible method of preventing such carryover from occurring might be 
to allow the milk line to be "flushed" with milk from the current group for a few minutes, before opening the flow regulator on the fluid line to start collecting a new sample from the current group. While the issue of carryover between successive groups of cows is probably not practically important in terms of its potential impact on accuracy and subsequent interpretation of milk component data, this question should be addressed, if possible, in future studies.

\section{CONCLUSIONS}

The results of this field study showed that milk samples collected from the QMI Safe Septum sani-elbow milk-line sampling device in a farm setting provide milk component results that agree very well with bulk-tank sample results collected from the same group of cows during the same milking. These results should not be extrapolated when considering the function of other available line sampling devices. These results support the use of this QMI sampling device in programs to monitor milk component information at the group level. This milk-line sampling strategy should provide producers with inexpensive, timely, and accurate information that will help to improve ongoing nutritional monitoring programs.

\section{ACKNOWLEDGMENTS}

Technical support and funding for this study were provided by the Department of Clinical and Population Sciences and the Udder Health Laboratory, University of Minnesota. The authors would like to thank the dairies that participated in this study, as well as Brian Cuperus, Mandy Harms, Karen Lorch, Adam Molitor, Paul Rapnicki, and Trish Roisum who assisted with collecting samples and laboratory work.

\section{REFERENCES}

Azzam, A. M., S. M. Azzam, J. W. Keele, and J. F. Keown. 1989. The economic value of dairy herd improvement information in a sample of midwestern dairy farms. J. Dairy Sci. 72:1296-1301.

Fetrow, J., B. Harrington, E. Henry, and K. Anderson. 1987. Dairy herd health monitoring. Part I. Description of monitoring systems and sources of data. Compend. Contin. Educ. Pract. Vet. 10:F389-F398.

Godden, S. M., K. D. Lissemore, D. F. Kelton, K. E. Leslie, J. S. Walton, and J. H. Lumsden. 2001. Relationships between milk urea concentrations and nutritional management, production and economic variables in Ontario dairy herds. J. Dairy Sci. 84:1128-1139.

Hof, G., M. Vervoorn, P. Lenaers, and S. Tamminga. 1997. Milk urea nitrogen as a tool to monitor the protein nutrition of dairy cows. J. Dairy Sci. 80:3333-3340.

Jonker, J., R. Kohn, and R. Erdman. 1998. Using milk urea nitrogen to predict nitrogen excretion and utilization efficiency in lactating dairy cows. J. Dairy Sci. 81:2681-2692.

Nelson, A. 1994. Information needs of the dairy industry for health and nutrition management. J. Dairy Sci. 77:1984-1991.

Oltner, R., and H. Wiktorsson. 1983. Urea concentrations in milk and blood as influenced by feeding varying amounts of protein and energy to dairy cows. Livest. Prod. Sci. 10:457-467.

SAS User's Guide. 1996. Release 6.12. Cary, NC.

Schepers, A., and R. Meijer. 1998. Evaluation of the utilization of dietary nitrogen by dairy cows based on urea concentration in milk. J. Dairy Sci. 81:579-584.

Studer, E. 1998. A veterinary perspective of on-farm evaluation of nutrition and reproduction. J. Dairy Sci. 81:872-876.

Wiggans, G. R. 1994. Meeting the needs at the national level for genetic evaluation and health monitoring. J. Dairy Sci. 77:1976-1983. 